\title{
Social Eating Initiatives and the Practices of Commensality
}

\begin{abstract}
Social eating initiatives are a mode of food provisioning and eating that have become increasingly popular in the UK. These organisations provide a menu of low-cost meals prepared using food surpluses and deliberately serve food communally to improve social inclusion. Although these community initiatives have grown rapidly in popularity, research into their value from the perspective of participants is currently limited. This article presents data from a concurrent multi-method study conducted across multiple sites of the Nottingham Social Eating Network to explain the emergence of these novel social configurations. The results show this form of commensality, or group eating practice, is not simply a consequence of reducing food waste or food insecurity. Instead these initiatives are enacted through a series of intersecting social practices, which include: the restructuration of the shared mealtime; alimentary contribution; and performances of care. The findings provide important insights into the values expressed in these emergent initiatives and are therefore useful for framing social eating in public policy.
\end{abstract}

\section{Keywords}

Social Eating; Commensality; Food Waste; Food Insecurity; Practice Theory; Alimentary Contribution 


\section{Introduction}

'Normative social influence on eating is potent and pervasive. The presence of other people at an eating occasion or when choices are made about food has a powerful effect on behaviour.' (Higgs 2015: 42)

'Through community dining spaces we create purpose, friendship and build resilience. When we sit and eat together barriers are broken down and new ideas can flow. The spaces being created are ones where anyone and everyone can eat in company' (National Food Service 2020).

People eat together in many different places, at many different events, and through many different stages of their lives. Commensality (literally 'eating at the same table') is an omnipresent manifestation of human sociality (Sobal 2000; Fischler 2011; Dunbar 2017). Eating together in groups is 'one of the most fundamental, socialised, imaginative and collectively invested biological functions' (Masson, Bubendorff and Fraisse 2018:109). Indeed, the organisation of society is continually negotiated through food practices in everyday and mundane forms (DeVault 1991; Grieshaber 1997; Valentine 1999; Yates 2015; Giacoman 2016; Holmes et al. 2020). But despite the perennial human need to eat in groups, the practices of commensality vary widely as a consequence of socioeconomic influences. In the UK, commensality is undergoing a transformation as a range of new initiatives emerge dedicated to creating new, shared eating practices. These 'social eating initiatives' which utilise surplus foodstuffs have been described as a response to rising food insecurity, a growing resistance to food waste (Baron et al. 2018; Luca et al. 2019; Blake 2019a, c), and as a form of surplus food aid redistribution (Dowler and Caraher 2003; Caplan 2017; Caraher and Furey 2017). But as yet there is limited empirical research examining how the 'potent and pervasive' forces of commensality (Higgs 2015:42) intersect with, and shape, this emerging phenomenon

The extant literature on food surplus redistribution services focuses on charitable food banks (Poppendieck 2014), surplus food pantries (De Souza 2019), or surplus-social supermarkets (Saxena 2018) which attempt to provide, in varying ways, food aid services for an individual 'poverty consumer' (Pfeiffer et al. 2015) excluded from the market of commercial food services. This literature critiques the effects of austerity politics and calls for dignity, choice and income to be re-instated (Dowler and O'Connor 2012; Lansley and Mack 2015; Lambie-Mumford and Dowler 2015; Purdam et al. 2016; Middleton et al. 2018), suggesting 
that the relationship between redistributing food surpluses to the food insecure is morally questionable (Caplan 2017; Caraher and Furey 2017). In particular, this discursive coupling creates a frame which would conceive of low-cost, low-choice, surplus meal services such as social eating initiatives, as another manifestation of food charity, and therefore frame the users of these services as beneficiaries of food aid. Scrutinising the long-term political consequences of surplus food redirection to the poor is of vital importance, and recent research into surplus food redistribution services has highlighted the need for further work which can articulate the experiences of citizens that may be 'below the level of consumption adequacy...' but who are nonetheless 'beneficiaries and co-creators of value' (Baron et al. 2018). But as yet there is limited empirical work which places the individual consumption of surplus food back into the social context of commensality or which addresses how participants forge new experiences of social value through the group consumption of surplus foods.

We address this gap in the literature through a practice theory approach; looking at 'social eating initiatives' not as a simple aggregate of individual consumer behaviours, nor as merely a reaction to austerity politics, but as form of group, commensal practice. We show that these initiatives create multiple points of social connection and are of value to participants because they counter the alienating and individualising tendencies of the current milieu to build group cohesion (Giacoman 2016). Although social eating initiatives use redistributed surplus foods, have limited menu choice, volunteer networks, and maximally inclusive pricing, the meals are not free, and the organisations do not operate through referral systems. Closer examination reveals that social eating initiatives support a hybrid form of commensality wherein the varying practices of domestic, charitable and 'eating out' commensality intersect. Attendants at these spaces are transforming practices of commensality, rather than just being passive beneficiaries of surplus food aid.

We introduce the Nottingham Social Eating Network, the case study for this article, as a localised example of a broader UK movement transforming the way communities eat. We then outline a community-based participatory research approach which deploys concurrent multi-methods to collect and analyse data generated by social eating participants. These include: (1) meal-centred focus groups; (2) go-along interviewing; and (3) photo voice. The process of examining eating as part of its social context, and placing the mealtime within the broader preparation, serving, and clearing down practices of the social eating initiatives articulates social eating as a 'compound practice' involving a range of coordinated activities that extend beyond any 'moment of individual consumption' (Warde 2016). We draw on the 
work of Shove et al. (2012) to analyse how the intersection of materials, competences, and meanings construct these practices. The results reveal how social eating initiative commensality is enacted through the practices of, a restructuration of the mealtime; alimentary contribution; and performances of care.

The results challenge framings of community food initiatives that use surplus foods as being places that give away 'leftover food for left behind people' (Riches and Gerlings 2019) and as solely concerned with reducing food insecurity and food waste. The results provide insights into the contemporary emergence of social eating initiatives and have important implications for including commensality in food policy debates. These analyses offer a more nuanced interpretation of the value that participants attribute to social eating initiatives; contributing to the 'more than food' approach' (Healy 2019; Blake 2019a, c; Marovelli 2019).

\section{Food insecurity, food waste, and surplus food aid in the UK}

In the UK, rising food insecurity exists simultaneously with industrial-scale food wastage, creating the iniquitous social problem of hunger despite food excess (Caplan 2017). Exacerbated by welfare retrenchment (Garthwaite, Collins and Bambra 2015; LambieMumford and Dowler 2015; Lansley and Mack 2015; Blake 2019a), food insecurity concerns the availability and access of individuals to foods that are socially and culturally appropriate, as well as nutritionally adequate (Radimer et al. 1990; Dowler and O'Connor 2012; LambieMumford 2015). Sharpe (2003) of the Food Poverty Network also considers a 'lack of money, or physical difficulty in getting to (or back from) suitable shops, or lack of equipment or cooking skills, or linguistic or cultural barriers' (2003: 31). In response, there has been an unprecedented scaling-up of food-provisioning organisations, conceived as 'food aid' (Lambie-Mumford and Dowler 2015), with those on low incomes having to rely increasingly on minimal diets, food charity and emergency provision (Riches and Silvasti 2014; Dowler and Lambie-Mumford 2015; Pfeiffer et al. 2015).

Against this backdrop, WRAP (2020) estimates that in 2018, 9.5 million tonnes of food were wasted within the UK, $70 \%$ of which was intended for consumption. Within the context of increasing environmental concerns about food wastage occurring parallel to austerity policies, and the rise in individuals experiencing food insecurity, it might appear that surplus foods provide a mutually beneficial adjunct to these social malaises by linking two 'needs' together (Lalor 2014; Caplan 2017). The current framing of surplus food-use is that of a waste stream redirected towards those experiencing food insecurity via initiatives such as charitable 
food banks (Caraher and Dowler, 2014; Caraher and Furey 2017). This surplus food aid provision is instrumental and individuated; responding to an individual's physical requirements for sustenance through free food parcels (Garthwaite, Bambra and Collins 2015; LambieMumford and Dowler 2015). The receipt of food aid positions individuals as passive beneficiaries, with little agency and choice over the foodstuffs they consume (Caplan 2017). In this way, surplus is conceived of as 'the second tier of our food system' (Tarasuk and Eakin 2005:178), where the individual receipt of surplus foodstuffs is a last resort, used only when necessary, and with the associated recipients feeling obligated, ashamed, and stigmatized (Dowler and O'Connor 2012; Loopstra and Tarasuk 2012; Lorenz 2015; Douglas et al. 2015; Garthwaite 2016). As redistributed surpluses become framed as a response to food insecurity, they also become framed in terms of deservedness, need and eligibility (Tarasuk and Beaton 1999; Tarasuk et al. 2014; van der Horst et al. 2014; Purdam et al. 2016; Garthwaite 2016; Williams et al. 2016; Middleton et al. 2017). Food insecurity is mediated through the eligibility criteria of charitable food banks (Poppendieck 2014), community pantries (De Souza 2019), or social supermarket membership (Saxena 2018). These criteria act as 'translation mechanisms' whereby those deemed 'in need' (Carson 2014) are defined through 'paternalist technologies and representations of deservedness' (Williams et al. 2016: 2294). Crucially, it is claimed that, within the context of austerity in the UK, community commensality has been diminished and responsibility has shifted from the state to the charitable sector (Caraher and Furey 2018), with charitable food projects instead rebranded as 'community food' (Dowler and Caraher 2003).

The way groups of people eat cannot be separated from broader debates about satiating hunger; directing us to consider how retrenchment of the welfare state, neoliberal economic policies and the dominance of the paying-consumer as the primary agent of society, distorts understandings of who and what is deserving or of value. The redirection of surplus to those struggling to afford food is therefore subject to an 'uneasy dualism' arising between 'quality food' for higher income consumers and 'other food' consumed by others (Holt-Gimenez and Shattuck 2011; Goodman and Goodman 2007). This conceptualisation ensures surpluses continue to be discursively framed in terms of deficit as 'poor people's food' (Caraher and Furey 2017; cf. Blake 2017). Though there are some exceptions of surplus-utilising projects such as FoodCycle and The Real Junk Food Project in the UK for example, that attempt to valorise and normalise the consumption of intended-to-be-wasted-food through, for example, the trope of environmental stewardship (Gollnhofer 2017) and social eating. In Europe, another example Eatwith seeks to reconstitute intimate, small-scale, supper club and dinner party 
'social' eating commensality. However, the 'social eating initiatives' described within this paper refer specifically to low-cost, paid-for, surplus meal offers, which are consumed at a public, shared mealtime (Luca et al. 2019).

Social eating initiatives encourage a broadened conceptualisation of what 'food security' is, particularly around the social nature of 'alimentary participation'. Alimentary participation concerns both physiological hunger and 'hunger for social inclusion' (Pfeiffer et al. 2015:485). It refers to 'the possibility of experiencing the social function of food, by eating outside the home, and/or together with others, [and] is something from which poor people are significantly excluded' (Pfeiffer et al. 2015: 488; Healy 2019). Recent research suggests that people with low incomes have limited capacity to engage in social eating activities and are thus excluded from an important aspect of social life (Dunbar 2017; Healy 2019). Although access and participation in social food practices such as 'eating out' and eating together are regarded as essential in modern and individualised consumer society (Dunbar 2017), according to Healy (2019), previous studies have largely omitted the social aspects of food insecurity (see also Pfeiffer et al. 2011).

Those experiencing this form of commensal-insecurity are often framed - as with food insecurity - according to a 'deficit' approach (Mathie and Cunningham 2003; Keller et al. 2015). Whilst these framings are not inaccurate, such epistemologies focus on top-down or structuralist accounts of insecurity, ignoring the innovative efforts of community groups to forge new forms of group eating practices through their own agency. Taken together, the issues of food insecurity, food wastage and the utilisation of food surpluses intersect as a site of social practice; constructed, negotiated and contested at multiple levels. Definitions of food insecurity are therefore mutable and are directly related to and created within specific historical, economic and political contexts. Food poverty is 'multi-faceted' (Healy 2019) and food insecurity is 'multivalent and always contested' (Shattuck et al. 2015:423). This extended conceptualisation provides an opportunity to reframe these intersecting issues to investigate the 'multidimensional values' (Iacovidou et al. 2017; Blake 2019b) embedded in social eating initiatives, particularly around alimentary participation. Following recent work in this area (Midgley 2013; Giacoman 2016; Marovelli 2019) we suggest that an alternative approach is to examine these practices through the lens of commensality, so that the social value of eating surpluses might be foregrounded. 


\section{Commensality and the structure of mealtimes}

'Interpersonal sharing of food has been an omnipresent feature of human civilisation from hunter-gatherer societies to the present, both as a mechanism through which sustenance is secured and as a means to cement social relations' (Davies et al. 2017:136). Food sharing has 'an aggregative potential that strengthens the social bonds and common identity of people sharing a meal' (Masson, Bubendorff and Fraisse 2018:109). Commensality involves the creation and reinforcement of social relations; nourishing the symbolic and material connections between people (Chou, Kerner and Warmind 2015). Indeed, communal meals are 'perhaps the single most important thing we could do - both for our own health and wellbeing and for community cohesion' (Dunbar 2017). The act of eating with other people helps to reproduce or transform the social order, fabricating new and consolidating old social connections; variously disrupting as well as entrenching social grouping, hierarchies and inequalities (Valentine 1999; Giacoman 2016; Dunbar 2017; Masson, Bubendorff and Fraisse 2018).

Aside from the contextual issues around food insecurity that undermine individuals attempts to eat healthily, regularly and with others, one problem potentially associated with food insecurity is a perceived ongoing destructuration of the shared mealtime (Warde 1999; Mestdag, 2005; Brannen, O'Connell and Mooney 2013; Lund and Gronow 2014; Yates and Warde 2017). Food insecurity and food waste in the UK occur within a broader foodscape, where the traditional structuring of mealtimes has undergone a transition to 'culinary plurality', as the breadth of individual and commensal eating practices continues to grow in diversity (Mäkelä 2009:45). Despite contradictory evidence that shared mealtimes are either under threat (Twine 2015), or instead being reconstituted in new forms (Yates and Warde 2017), it is nonetheless widely agreed upon that commensality is a potent normative feature of UK society (Mestag 2005; Brannen, O’Connell and Mooney 2013; Dunbar 2017). The prevalence of cheap, mass-produced, individually portioned, fast-food and snacks offers in contemporary UK foodscape have been described as restructuring (and in some cases replacing) the freshly cooked and shared family mealtime (Twine 2015). Similarly, Fischler (1988) described this de-centring of the meal, and particularly the accompanying rise of lone-eating, as 'gastroanomie'. But specific reference to commensality as a form of social practice provides a sharper focus than more abstract references to consumption, which Warde (2005) suggests is simply a 'moment' in social practices. Referring to the general process of consumption, rather than to the specific practice of social eating, tends to position 'consumers' in reductive terms as 
individuals whose main purpose is to buy and consume goods. Focusing on the practice of commensality directs us to consider what we eat, the material and symbolic properties of foods, their preparation, serving and wasting, as well as the aspects of food sharing. As noted by Schatzki et al. (2001:3) 'understanding specific practices always involves apprehending material configurations'. Therefore, being sensitive to the ways in which commensal practices emerge or are 'carried' within constellations of 'things' requires a different ontological position (Farias and Bender 2010; Farber 2014).

Recent research into commensality (Giacoman 2016) suggests there is a dynamic interplay between social groupings and the form commensality takes. The features of the group affect the form of commensality that manifests and vice versa. Giacoman (2016) notes that the 'group's characteristics will influence the way in which commensality is manifested... and the positive or negative feelings shared by those who are part of the group'. Further, that groups are situated in particular settings and locations, affecting how commensality materialises. We recognise the dynamic relation between social structure and forms of commensality in Giacoman's model, but also recognise the material dimension of food and how these shape eating practices. As Shove et al. state, 'in doing things like... cooking, people actively combine the elements of which these practices are made' (Shove et al. 2012:14). We suggest therefore that Giacoman's account of group-commensality dynamics can be augmented by considering how the practices of commensality rely on a combination of elements that include: materials, competences, and meanings (Shove et al. 2012:14). In Table 1 we outline how each these elements can potentially contribute to varied practices of commensality: 


\begin{tabular}{|l|l|l|}
\hline Elements & \multicolumn{1}{|c|}{ Definition } & \multicolumn{1}{c|}{ Illustrative Examples } \\
\hline \multirow{3}{*}{ Material } & $\begin{array}{l}\text { The things, technologies, } \\
\text { tangible physical entities and the } \\
\text { stuff of which objects are made }\end{array}$ & $\begin{array}{l}\text { Surplus foods; Tables and chairs; } \\
\text { Funding streams; Policies; Ingredient- } \\
\text { sorting; Meal prices and meals }\end{array}$ \\
\hline Competences & $\begin{array}{l}\text { The skills, know-how, and } \\
\text { techniques used to enact } \\
\text { practices }\end{array}$ & $\begin{array}{l}\text { Volunteering to wash up; Being a cook; } \\
\text { Meal preparation styles; Showing table } \\
\text { 'manners'; Engaging in conversation; } \\
\text { Paying for meals; or being the point of } \\
\text { contact between the organisation and the } \\
\text { food distribution charity }\end{array}$ \\
\hline \multirow{3}{*}{ Meanings } & $\begin{array}{l}\text { The social and symbolic } \\
\text { significance of participation at } \\
\text { any one moment. }\end{array}$ & $\begin{array}{l}\text { The symbolism and meaning attached to } \\
\text { the 'family meal'; the value placed on } \\
\text { eating together; and the value of sharing } \\
\text { food, going 'out' for a meal }\end{array}$ \\
\hline
\end{tabular}

Table 1: Elements of social practices and illustrative examples for group eating, informed by Shove et al (2012)

The range of elements involved in social eating initiatives overlap within practices, elsewhere referred to as 'bundles of activities' (Martens 2012), and attention must be given to the complex and intersecting ways that these elements are combined. Social eating initiatives combine tangible things, material resources, ways of acting and doing, stories, symbols, and meanings within a social context (Halkier and Jensen 2011; Shove et al. 2012). Indeed, some of these practices overlap with each other, creating 'compound practices' that 'pre-form, form and reform and de-form' (Pantzar and Shove 2005). Analysing the elements that constitute social eating practices in collaboration with participants, and framing both the producers and customers of social eating initiatives as participants, reveals the ways social eating is constructed and valued. We address these participants in the section that follows.

\section{The research context: The Nottingham Social Eating Network}

In 2017, Nottingham City Council declared its support for Nottingham to be recognised as the UK's first social eating city (BBC 2018). This declaration was a response to the growing number of community groups participating in a specific form of mealtime practice, referred to locally as 'social eating'. Luca et al. (2019) define social eating initiatives as 'communitybased initiatives that provide an integrated model for recovering and using surplus food, 
localizing food and providing spaces of interaction that can address food insecurity, support health, well-being and social capital. Generally, these social eating projects... cook and provide nutritious meals in a community venue for a suggested donation of, for example, $£ 2.50$ per three course meal for adults; children eat for free. The meal is generally offered once a week in venues such as children's centres, community centres and churches'.

These initiatives operate as non-profit organisations. The meal is a paid-for offer with discretionary free meals available, rather than a free meal via referral. They have limited opening hours and reclaim spaces which otherwise serve different functions at other times in the day, such as church halls. The provisioning is typically overseen by a skeleton staff, with support from a broad ensemble of volunteers managing how food is served, participants are greeted, spaces are organised, entertainment provided, and dishes cleaned. In Nottingham, there are 14 self-identified 'social eating initiatives' informally known as the Nottingham Social Eating Network, and these were the focus of the study (an example can be seen in Figure 1). This local network also links in with the National Food Service network through the copromotion of the public consumption of surplus foods for social good.

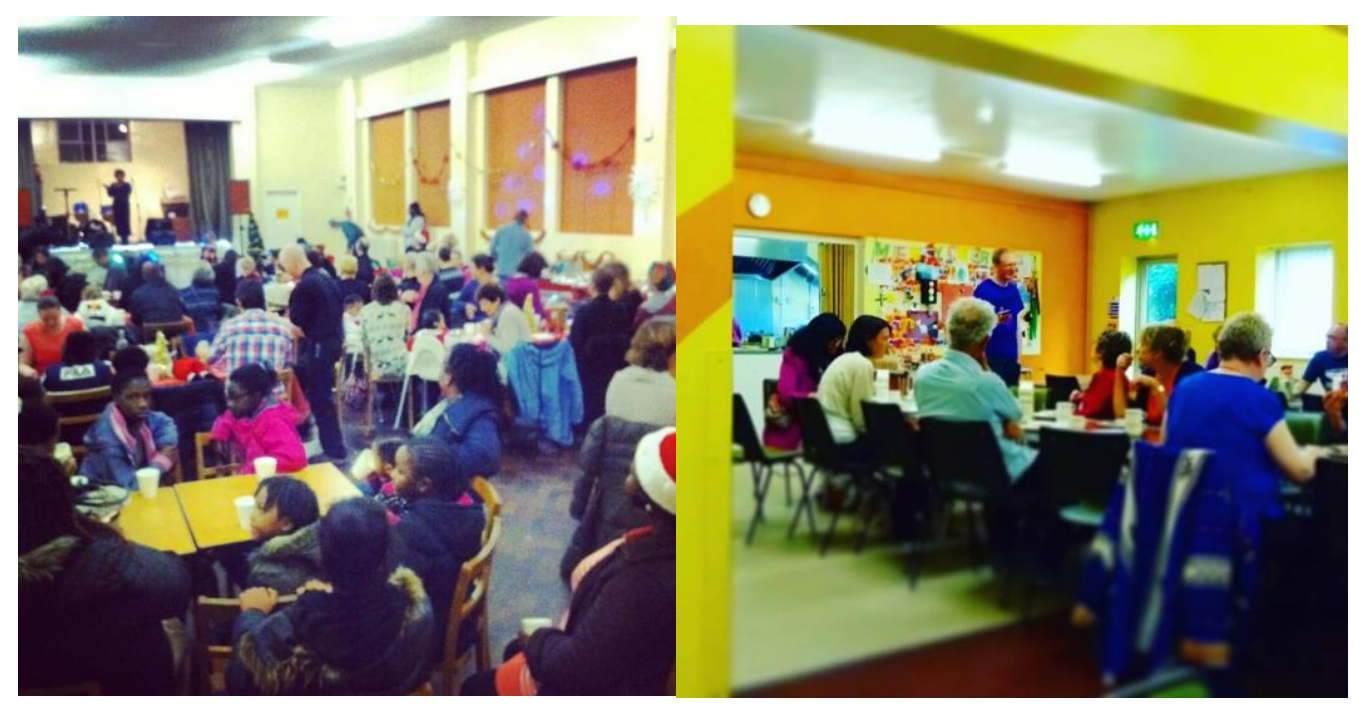

Figure 1. Photographs of Growin' Spaces and Sharing Sherwood social eating initiatives.

\subsection{Research Questions}

Despite the growing number of social eating initiatives - across Nottingham and the UK more generally - there is nevertheless limited available data on their contribution to the broader 'foodscape' (Coveney 2013). Similarly, there is a lack of empirical research that examines how participants in these initiatives attribute value to group eating practices. Our research design 
combines concurrent multi-methods conducted across multiple field sites to study how participants themselves articulate their modes of participation in these initiatives. Our aim is to understand the value these participants derive from the novel social eating practices they have created, but also to understand the broader concomitant social contexts that support commensality. We set the following research questions:

\section{RQ1 - What is the value of social eating initiatives to their participants?}

Following recent work on commensality and the anticipatory practices of using surplus food (Midgley 2013; Giacoman 2016; Marovelli 2019) we aim to extend this literature by examining new social eating initiatives. Here we are interested in understanding the values described by social eating participants within the broader social groupings they form. The aim is to create an inclusive method such that a range of respondents can describe and compare their own commensal participation with each other. By engaging participants in the natural setting of mealtimes, sharing food during discussions, and asking the respondents to inductively code their responses in situ with the people around them, we identify communal values of group eating expressed whilst the group is eating together.

\section{RQ2 - How do these values frame the eating of surplus food in relation to the broader commercial and charity foodscape?}

Extending the academic literature which frames initiatives that use surplus food as a form of rebranded food aid, we draw upon Shove et al.'s (2012) elements of practices to consider the bundles of commensal activities observed and described by participants during data collection. This question moves from an inductive focus led by the participants themselves to an abductive mode of theorising about commensality beyond any individual social eating initiative. This approach responds to the lacuna in empirical work on social eating initiatives specifically, and more broadly these findings help substantiate the 'more than food' literature (Pfeiffer et al. 2015; Healy 2019; Blake 2019a, c) where well-being and commensality (Block et al. 2011; Iacovidou et al. 2017) are considered alongside food insecurity, food wastage and community food services. In the following sections we outline our approach to sampling before describing the series of methods implemented concurrently and repeated across multiple sites. 


\section{Sampling and Data Collection}

Nottingham currently has 14 self-identified social eating spaces based across the city and its suburbs, and within the wider county of Nottinghamshire (Social Eating Network 2020). 9 of the 14 social eating groups approached were available to engage in the study and 7 of the groups helped organise community workshop research events involving customer participant groups in-situ ${ }^{1}$. No specific exclusion criteria in sampling were applied as the network itself selfselects members based upon the provision of affordable meals which utilise surplus foodstuffs, are open to the public, and provide a meal at a set mealtime. To help demonstrate the diversity of the network, a brief description of five examples of social eating initiatives are provided in Table 2 based upon fieldwork observations and local government statistical data on indices of deprivation and poverty (Nottingham City 2019).

Overall, Nottingham is an area of high, multiple deprivation and has, for example, the UK's lowest rate of disposable income (Lawton 2017). This broad-brush picture of the city frames it as an area where social eating initiatives may have proliferated due to food insecurity; replacing community commensality with charitable commensality. However, as the table shows, the variety of projects offering social eating meals demonstrates that whilst there are for example, church groups who emphasise the charitable giving of food, social eating initiatives are not primarily about charity. Nor do the organisers and attendees of social eating initiatives in Nottingham fit neatly within any single determinant category of demography, social class, economic wealth, or religious membership. As their name suggests, they are more easily characterised by how they arrange eating rather than who they preclude from eating.

\footnotetext{
${ }^{1}$ Bestop Kitchen, Secret Kitchen, Carriages Café, Parkgate Community Café, Soul Food Café, Sharing Sherwood, Growin' Spaces engaged in meal-centred focus groups. Secret Kitchen, Carriages Café and Parkgate Community Café also engaged in go-along interviews and photography. And Bestop Kitchen, Secret Kitchen, Carriages Café, Parkgate Community Café, Pulp Friction and Sycamore Diner all contributed to the photovoice exercise.
} 


\begin{tabular}{|c|c|}
\hline $\begin{array}{l}\text { Social Eating } \\
\text { Initiative }\end{array}$ & Description \\
\hline $\begin{array}{l}\text { Bestop } \\
\text { Kitchen }\end{array}$ & $\begin{array}{l}\text { This is a Church group that runs a weekly social eating event and a monthly family meal. It offers table service and tables set out in longer, canteen-style } \\
\text { arrangements. The group is also developing a community allotment and is partnering with a local vermiculture project to compost local food waste. Meals are } \\
\text { paid-for, the project has a mixture of paid staff and volunteers. Bestop Kitchen is based in Bestwood, North Nottingham City. Bestwood is an area classed within } \\
\text { the city council literature as an area of high deprivation. This is a primarily white family and elder group with a number of customers with physical disabilities } \\
\text { and mental health conditions. The weekly lunch has an average of 30-80 attendees. }\end{array}$ \\
\hline $\begin{array}{l}\text { Secret } \\
\text { Kitchen }\end{array}$ & $\begin{array}{l}\text { Based in Newstead, Nottinghamshire, a predominantly white, working class and deprived ex-coal industry village, Secret Kitchen runs a monthly social eating } \\
\text { event on a Saturday evening and additional events across Nottingham. It is a family-run social enterprise offering social eating events, cooking education, and } \\
\text { surplus catering. Meals are paid for. There is a mixture of customers ranging from families, elders, individuals eating alone to large groups eating together. } \\
\text { Customers travels from across the city to attend. The monthly event is well-attended; often with around } 80-100 \text { customers and has a busy, noisy and highly } \\
\text { sociable atmosphere as customers sit around large, circular tables to dine. }\end{array}$ \\
\hline $\begin{array}{l}\text { Carriages } \\
\text { Café }\end{array}$ & $\begin{array}{l}\text { Based in relatively wealthy Newark, Nottinghamshire, Carriages Café is a conventional, commercially operated café which runs a bi-monthly social eating meal } \\
\text { in the evenings, after the conventional café closes. The meal is paid-for but they accept monetary donations according to what the customer can afford to pay, } \\
\text { and they also offer discretionary free meals. The customers range from people who are homeless to groups of elders. Around } 40-50 \text { customers enjoy table service } \\
\text { in pleasant surroundings and free, additional food parcels are available to take away when there are surplus-surpluses such as short-dated items which will not be } \\
\text { used by the time of the next event. }\end{array}$ \\
\hline $\begin{array}{l}\text { Soul Food } \\
\text { Café }\end{array}$ & $\begin{array}{l}\text { In inner city Radford, Nottingham, Soul Food Café offers a mixture of ethnic and traditional UK cuisines from a Church hall space. Soul Food attracts a diverse } \\
\text { array of around } 30 \text { customers from students, local residents, food bank attendees, its Church congregation and members of a local arts hub to its } £ 2 \text { weekly lunch } \\
\text { offer. }\end{array}$ \\
\hline $\begin{array}{l}\text { Sharing } \\
\text { Sherwood }\end{array}$ & $\begin{array}{l}\text { Sharing Sherwood's primary focus, as communicated by its customers, is to reduce food waste, highlight sustainable eating practices, and provide a monthly } \\
\text { meal for the local community. Sherwood is relatively wealthy and although the meal operates by suggested donation, they raise enough money via their monthly } \\
\text { Sunday evening meal to regularly donate to a local food bank. }\end{array}$ \\
\hline
\end{tabular}

Table 2. Description of social eating initiatives. 


\section{Methodology and Research Approach}

There has recently been a renewed and reinvigorated exchange of ideas across sociology and participatory design. This dialogue between disciplines has emerged from a shared interest in 'community sensing' (Le Dantec and DiSalvo 2013), where researchers attempt to engage and conceptualise how groups of people enact local and systemic change (Ehn 2008; Björgvinsson et al. 2010; DiSalvo et al., 2012; Le Dantec and DiSalvo 2013). The Community-Based Participatory Research (CBPR) approach seeks to involve community members in the research process, producing forms of knowledge that are relevant, useful and/or driven and directed by community partcipants (Chung-Chun et al. 2005; Reason and Bradbury 2006; Faridi et al. 2007). Community workshops (Kindon et al. 2007; Beebeejaun et al. 2014; Moragues-Faus and Marsden 2017) are a means of better understanding the factors that may be decreasing, or at least influencing, experiences of social cohesion. Within the UK context of welfare retrenchment, community groups are vital sources of knowledge concerning the strategies deployed locally to mitigate these challenges (Cloake et al. 2017; Blake 2019a, c; Luca et al. 2019; Marovelli 2019).

CBPR encourages participants to 'reconsider previous views on certain topics', 'challenge pre-conceived ideas' and encourages 'new ways of looking at old problems' (Doyle and Davies 2013:269). We submit that this approach is appropriate for revealing the value of social eating to participants and how these values challenge the current framing of community food initiatives that use surplus food as a form of food aid. The methods chosen sought to capture the complete mealtime beyond any 'moment of individual consumption' (Warde 2016) and to foreground the insights of participants through a combination of data gathering techniques. The research was conducted over a period of six months during 2019. Research ethics for the study were designed in accordance with the policies of Coventry University (Coventry University 2020).

\subsubsection{Meal-centred focus groups}

Social eating initiatives are frequented by a broad range of people, some of whom are often attending for the first time. The research method was thus designed to be maximally inclusive, such that participants could move freely in and out of the research setting as they pleased and so group discussion could occur in a free-flowing format whilst people enjoyed food. These 
relaxed inclusion criteria enabled participants to eat as they would do normally in the space whilst maximising the sample size available for the study. 7 meal-centred focus groups were conducted, each in different venues, with groups ranging in size from 8 to 40 people. In total around 150 people took part in the activity.

As participants arrived at the social eating initiatives they were asked if they were willing to contribute to the ongoing research activity and after collecting their food were asked to write down on a post-it note the values they associate with or attach to the experience. These individual post-it note insights were placed on a whiteboard and then arranged through group discussion into broader themes. The themes were then given titles such as 'networking' or 'community spirit' by the participants themselves (as seen in Figure 2). The activity is thus 'grounded' insofar as the community coding of focus group responses generates axial codes with limited assistance from the research team. The resultant open and axial codes from each focus group were subsequently combined to give a broader comparative view of social eating initiatives across the city. These insights were further augmented by a series of more direct data gathering activities which we now describe.
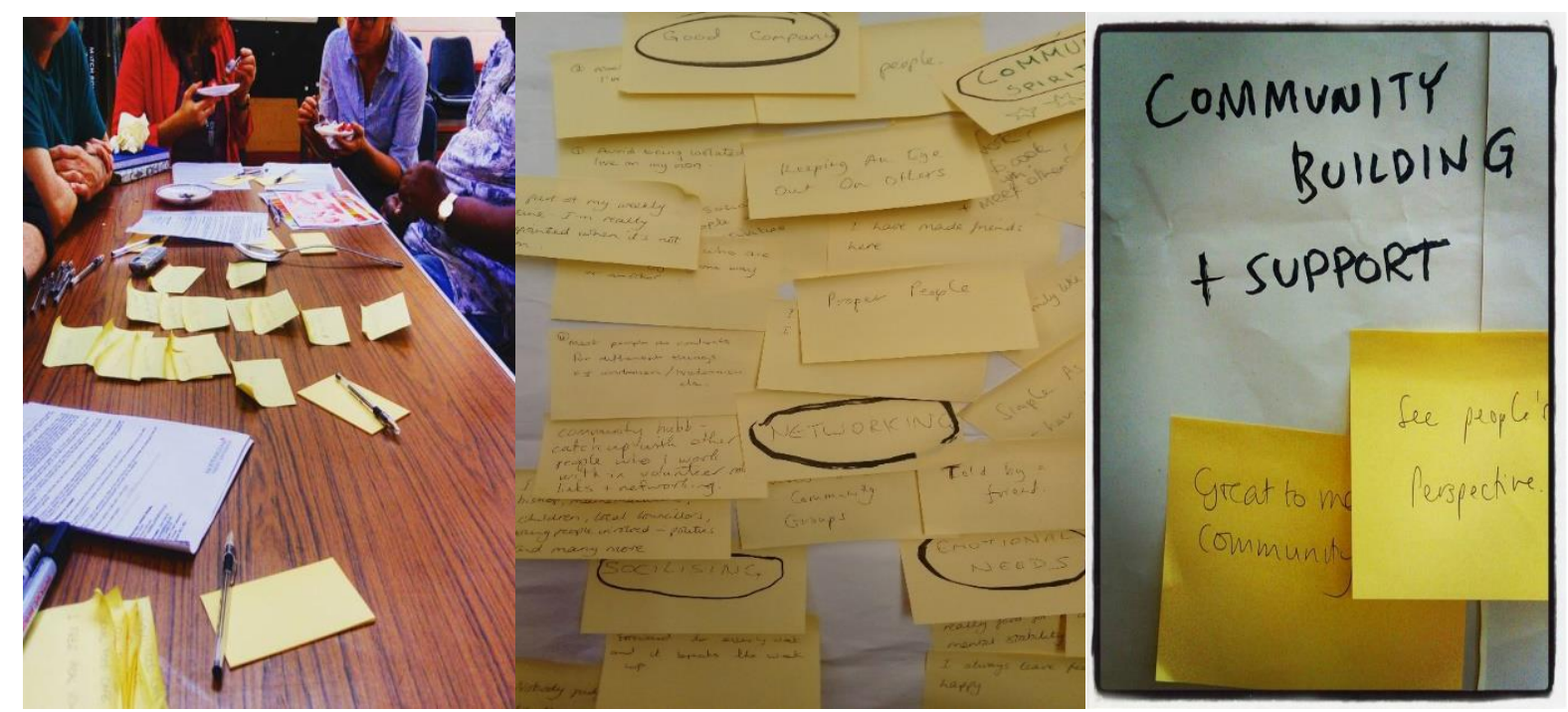

Figure 2. Photographs from the meal-centred focus groups.

\subsubsection{Go-Along interviewing}

Go-along interviews are 'a form of in-depth qualitative interview method that, as the name implies, is conducted by researchers accompanying individual informants on outings in their familiar environments' (Carpiano 2009:264). Interviews were conducted in 3 of the social 
eating initiatives with 13 participants. During the interviews participants were asked to 'show' the researcher the space as the mealtime proceeded. Go-along interviewing enables the participant and researcher to construct a 'stream of experiences and practices as they move through, and interact with, their physical and social environment' (Kusenbach 2003: 463; Jones et al. 2008). This is particularly important for social eating initiatives which vary significantly in terms of physical layout, order of service, and associated social arrangements. Go-along interviews were transcribed alongside a series of observational insights recorded as field notes. As the interviews proceeded photographs were taken to help record the physical and social arrangements present in each space, illustrative examples can be seen in Figure 3.
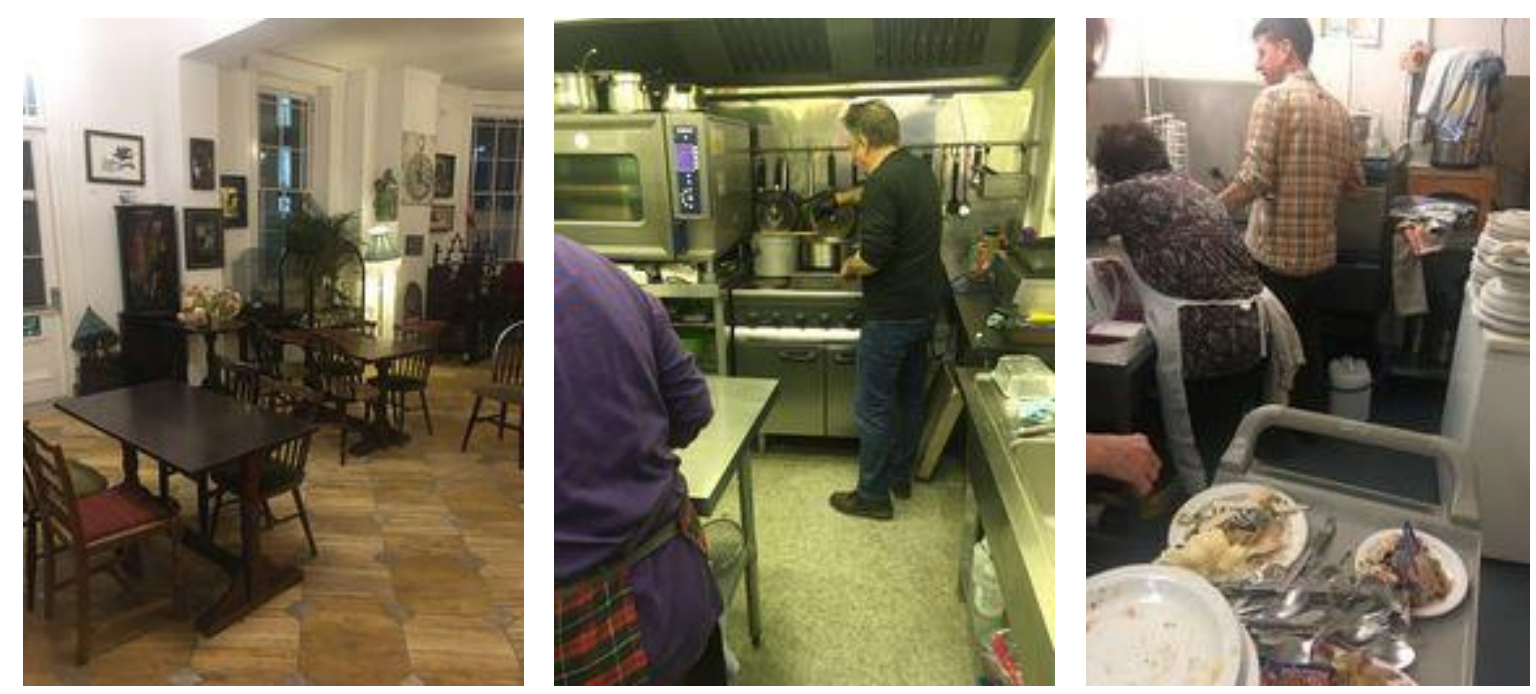

Figure 3. Go-along interview photographs showing the set-up of the dining room and kitchen organisation of Carriages Café; and kitchen and washing up activities at Secret Kitchen.

\subsubsection{Photo Voice}

Methods such as interviews or diaries often inherently conceal the performative or habituated aspects of practice (Halkier and Jensen 2011) and the intricacies that might exist between 'carriers' of practices (Goffman 2002 [1959]). As Martens (2012) contends, relying on talk about practices tends to reduce the meaning and significance of a practice to an individual and therefore potentially misses out on the ways in which contexts direct practice (Mannay 2010). To compliment the insights generated through meal-centred focus groups and go-along interviews a photovoice technique was conducted with 6 producer participant groups. These aimed to uncover phenomena that are mundane, taken for granted or difficult to verbally articulate (Power et al. 2014; Reid et al. 2018) such as customers moving tables around so they 
could sit together. Particular attention was given to the set-up, service and clear-down of the meal and how the spaces were arranged, moved-through and used. Participants at these organisations were asked to complete a photo-diary over a few weeks, taking photographs of whatever content matter they thought captured their day-to-day activities. This produced 117 images which ranged from food deliveries, and food sorting, storage, preparation, cooking and serving. Images of travel arrangements for elder customers, of the set-up of the dining room, volunteers 'showing off' the meals they have prepared, the kitchen facilities, queues, people washing up or moving tables and chairs were all captured and sent in for analysis (see Figure 3. and 4.) These photographs were accompanied by brief emailed notes where participants explained and clarified the content. This data was subject to open coding, including utilising the participants accompanying notes, to identify, name and describe content.

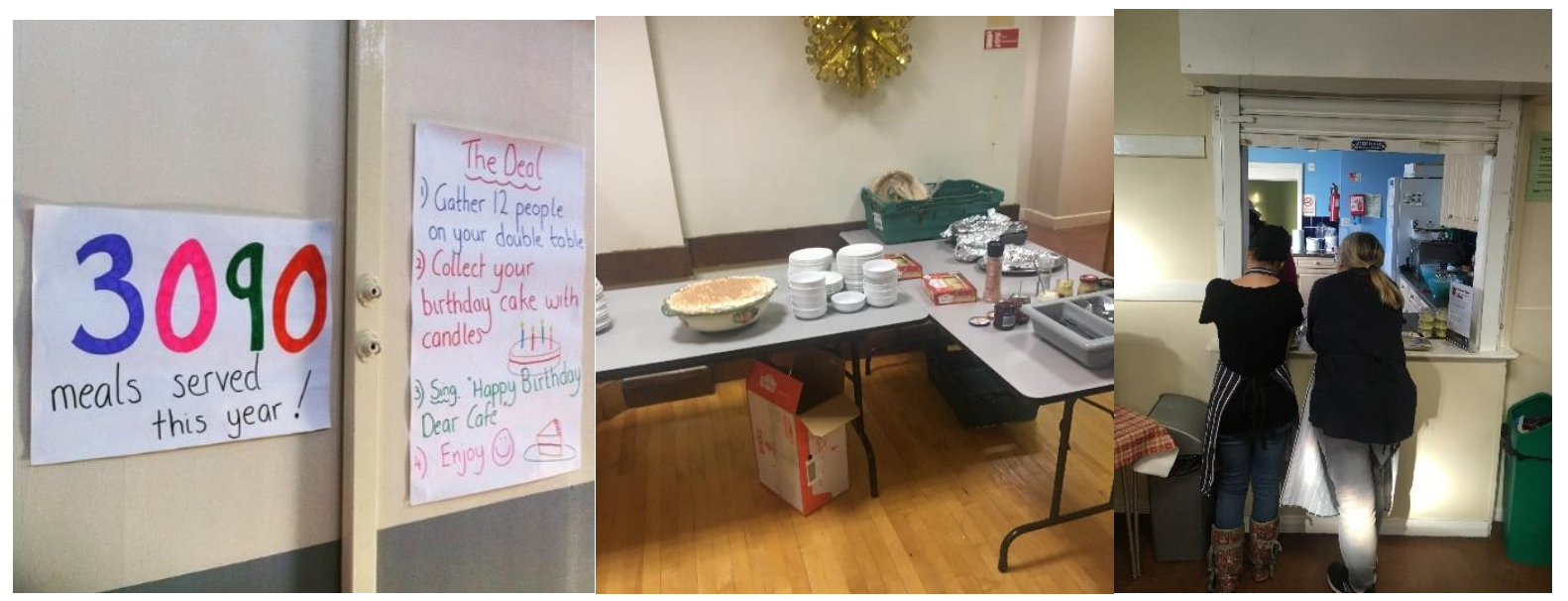

Figure 4. Photovoice photographs, various locations.

\subsection{Coding and formative findings}

The overall aim of the coding and data structuring process was to develop a comprehensive depiction of a social eating initiative, as articulated through the key words, photographs and terms submitted by participants. The data was coded and analysed through a grounded-theory approach (Strauss and Corbin 1994, 1998). A modified Straussian version of grounded theory was used where skeletal theoretical frameworks guided the investigation (Strauss and Corbin 1997, 1998), this was preferred in contrast to approaches which aim to discover underlying theory exclusively through systematic analysis of data (e.g. Glaser 1978). During the keyword and content coding, additional, practice-theory informed codes (following Shove et al. 2012) were developed to articulate some of the facets of social eating initiatives that were not explicitly stated by participants but nonetheless featured in the data. In this way, a mix of 
participant-generated and theoretically informed codes were integrated to reflect the arrangements of materials, competences and meanings present throughout social eating initiatives. An overview of the research design can be seen in Figure 5.

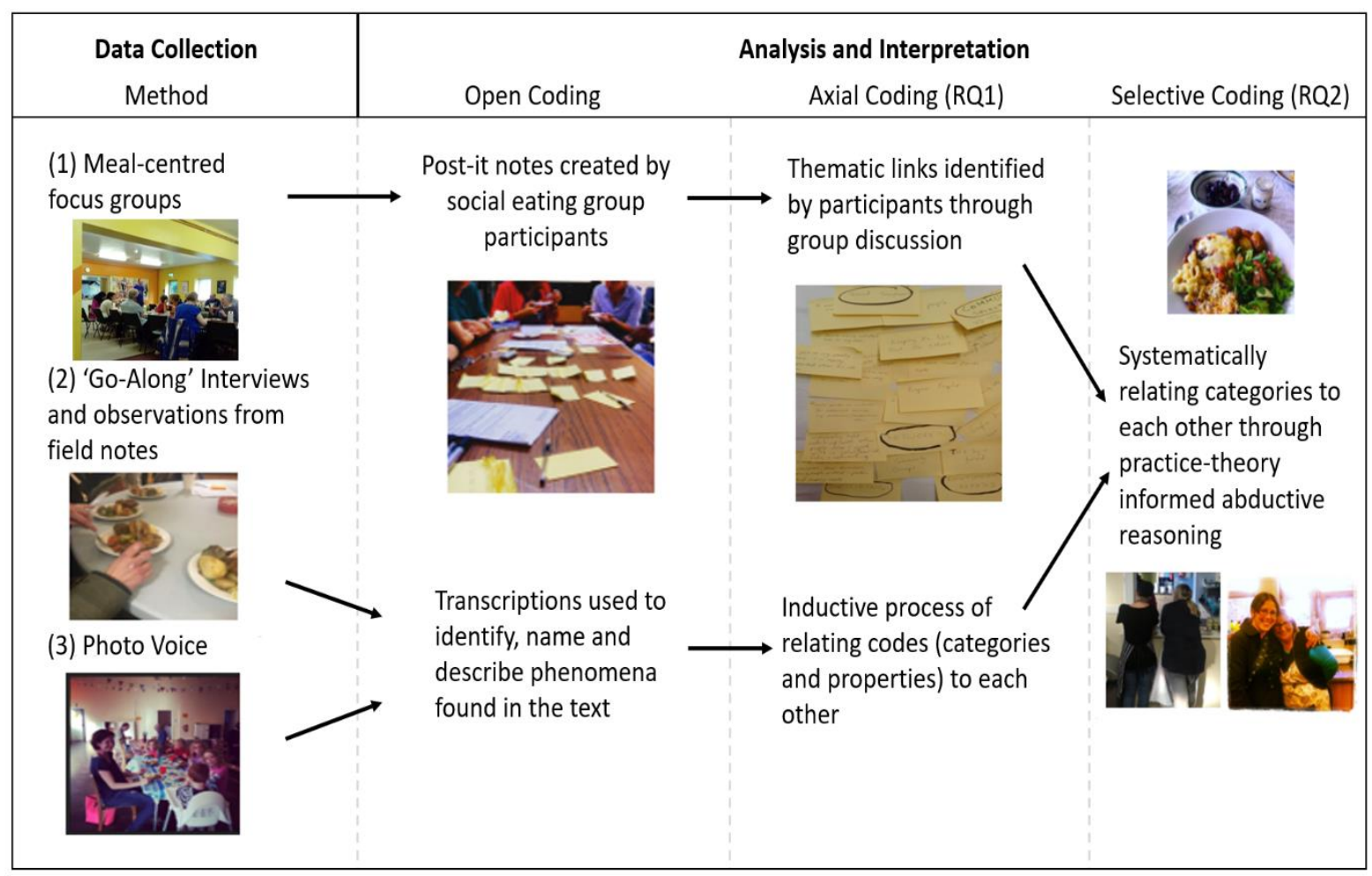

Figure 5. Research Design Overview

The open coding of the data by participants confirms previous rich descriptions of social eating initiatives as 'spaces of interaction that can address food insecurity, support health, well-being and social capital' (Luca et al. 2019). Axial coding was used to inductively sort data into core themes such as 'food, service and organisation' and 'socialising'. Selective coding, guided by fieldwork observations, then occurred wherein themes, coded according to social dimension (Shove at al. 2012), were distinguished into three distinctive but intersecting practices. What became apparent during fieldwork was that aside from the expected feature of social eating as a valued-form of eating a meal together, social eating initiatives both required and facilitated a range of social activities, interactions and materials that distinguished them from other community food initiatives that utilise surplus, foods such as charitable food banks and surplussocial supermarkets. We describe these social eating practices as (1) the restructuration of mealtimes, (2) alimentary contribution, and (3) performances of care. 
In the following section we present these three practices as montages which visualise the coded data alongside selected verbatim quotes, and display photovoice and go-along interviews photographs. These montages are intended to convey the rich practices, as identified by participants, that constitute and 'go into' a social eating initiative. Discussion of both research questions are presented alongside each other to provide (a) insight into the values experienced and enacted by social eating participants, and (b) evidence on the broader social practices which support these initiatives.

\section{Discussion}

\subsection{The Restructuration of Mealtimes}

"Sometimes it feels like the only time we had a family meal all week, as we're often too busy to eat together." (Interviewee)

The destructuration of traditional shared mealtimes can be seen as an 'ex-practice' (Shove et al. 2012: 25), where the links between the meanings, competences and materials used to sustain meal sharing practices are no longer made. The rise in fast-food consumption (Twine 2015), difficulties in scheduling shared meals (Yates and Warde 2017), and the rise in food 'translation mechanisms' between the State and the individual e.g. charitable food banks (Carson 2014; Williams et al. 2016), can all contribute to a perceived destructuration of the shared mealtime. These issues intersect in particularly acute ways for those experiencing food insecurity due to issues around the affordability, accessibility and availability of food, the framing of surplus as waste, and the practices of deservedness and eligibility; all of which affect participation and contribution to commensal practices. In contrast, social eating commensality can be understood as a form of novel social restructuration which has value for participants; encompassing 'more than food' (Pfeiffer et al. 2015; Healy 2019; Blake 2019a, c) and involving a range of activities that act contra to these broader, perceived destructuring tendencies.

In the following montage we see volunteers awaiting the influx of customers, the seating arrangements, the offer of pay-as-you-feel food as an additional social eating service and the serving layout as one social eating initiative gets its meal underway. Quotes illustrate the varying ways that commensality intersects with, and facilitates, the social life of customers, and the codes produced through data analysis are provided to show the rich array of phenomena 
and the linkages between them, that 'go into' the construction of a social eating eventconceived of as materials, meanings and competencies (Shove et al. 2012).

Eating Together- examples of codes understood as elements and linkages of practices

Materials Elements- Food, Surplus, Hall, Kitchen, Tables and chairs, Storage Space

Meanings Elements- Good food, Convenient, Choice, Fresh, Home cooked, Food quality, Made with love

Competencies Elements- Food collection, Measuring, Mis en place, Washing up, Set up space, Entering space,

Sit together, Getting out of the house, Routines, Attendance.

Linkages from the domestic sphere- Meaitime, Home cooked, Family meal, Bonding over food

Linkages to food insecurity- Free food, Free items, Pay it forward, Beneficiary, Eligibility

Linkages from eating 'out- Entertainment and music, Food service, Menu, Three-course, Choice

\section{Compound Practice of Commensal Restructuration}

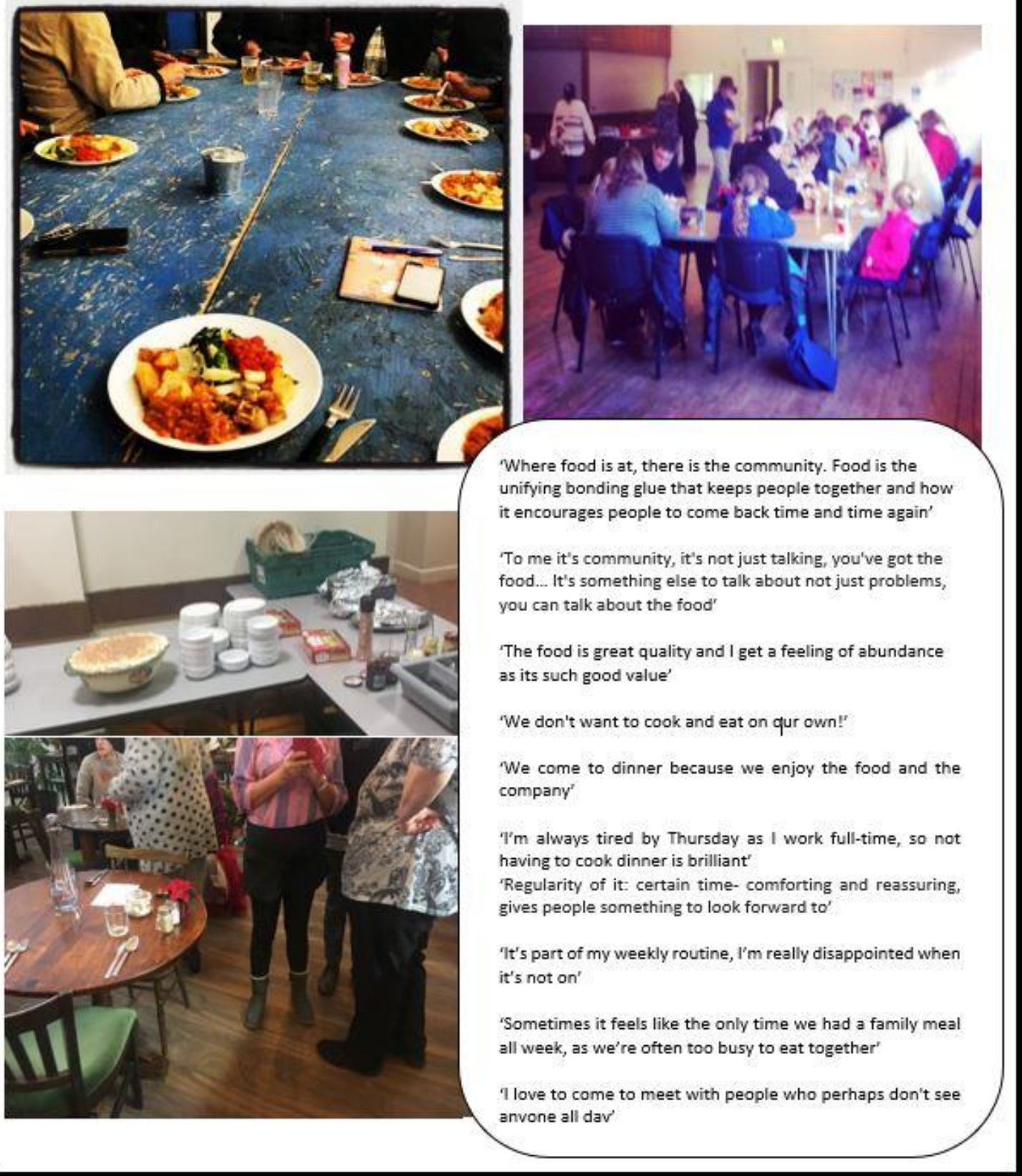

Figure 6: Commensal restructuration montage 
Just as commensality is a 'mechanism through which sustenance is secured and as a means to cement social relations' (Davies et al. 2017:136), the data illuminates how social eating initiatives go far beyond eating. A customer states that "I get such a lot out of it. It motivates me to get up in the morning as I have something to look forward to": commensality here, is implicated in the organisation and structuration of temporal rhythms (Maguire et al. 2015), which in turn intersect with performances of presentation and identity: "I feel it difficult to talk sometimes but there is never any pressure here". Elements from the domestic sphere find expression in social eating initiatives, for example in the terms described by participants: the scheduled and 'routinised mealtime', the 'three-course', 'homemade' meal, everyone eating the same food, the arrangement of 'tables and chairs' to facilitate 'conversation'- all of which sustain links with the familiar and familial. One customer described the pleasure in not having to cook, one expressed relief about not having to plan dinner, and one noted the challenges in accommodating her children's food preferences: "take the weight off eating with kids (eat your veggies etc.)". In this way, social eating commensality mobilises alternative performances of parenting, for example.

These activities engender eating practices that feel 'welcoming', 'warm', 'safe' and 'sociable'. Roles are carried over, pre-formed, from the domestic sphere and are reformed in social eating initiatives through the provisioning of 'fresh', 'healthy', 'balanced' and 'nutritious', 'homemade' meals. Simultaneously, elements from the practices of 'eating out' get carried over into social eating initiatives, for example: the material practice of going out to eat a paid-for meal that is made by someone else, being served food, or eating with strangers. Customer participants all eat the same meal, at the same time, for the same price; constituting a novel form of public mealtime where commensality is created through the mixing of both familiar and new elements.

The materiality of surplus food also affords the possibility for new practices to emerge. Surplus can be understood here as an actant whose affordability, perishability and variability creates specific materials effects, demands new competences and affords new meanings (Shove et al. 2012; Midgely 2014; Blake 2019b). Surplus food, decoupled from the commercial requirement to sell uniform portions of food at a profit, engenders expressions of abundance, generosity, for example: "what we tend to do is give out seconds of meals; some people want take-away because they can't eat a lot in one go, but other people stay and have three or four platefuls of food, and I'm quite happy for them to have more than one serving because I don't want food to go to waste". Surplus shapes the material practices of food collection, preparation, 
serving and menu creation which simultaneously articulate new discourses around food choice, availability, accessibility and affordability. As one participant noted: "The food is great quality and I get a feeling of abundance as its such good value. I feel comfortable enough to eat. It makes it possible to have a special family meal on a tight budget".

The variability and perishability of surplus food ensures meals are prepared 'fresh', often with a side table of short-dated items that customers are encouraged to take to prevent edible food entering landfill. In this way, the discursive link between surplus as waste food associated with food insecurity and food poverty is decoupled. Instead, surplus is used within social eating practices to construct practices of resource stewardship, food socialisation and food literacy; reframing its consumption as a choice and even as a form mutual aid.

Social eating initiatives are a site of commensal restructuration that is contra-food waste, contra-fast and junk food, and which supports routinised opportunities for participants to eat together in local spaces while enriching the social experiences of other participants. This claim is further strengthened when we consider the compound practices of helping out, or alimentary contribution, that distinguish social eating initiatives from other forms of community food provision that utilise surplus foods.

\subsection{Alimentary Contribution}

"Every person has an opportunity to bring the skills and experience and the talents, and we share those locally, and when I saw that, I thought 'that's a social eating event'. " (Interviewee)

"People are willing to offer what they can do (especially food-wise) and not worry about what they can't." (Interviewee)

The next montage again illustrates the compound of social eating initiatives practices. Whether it is the multiple volunteers preparing vegetables, the greeter who volunteers to take meal payments at the door, the servers waiting to take meals to diners or the middle images of customers moving tables so they can eat with another group, social eating initiatives are constructed through myriad practices of contribution and participation.

Opportunities to help out either directly or indirectly were recurrently mentioned; directing the development of increasingly specific codes such as 'worthwhile cause', 'civic opportunity' and 'service to the community'. As data analysis progressed, the compound 
practice (Warde 2016) of alimentary contribution could be discerned: "everyone participates at some level and gets something out of it".

The low-cost, paid-for, or paid-forward meal offers enact experiences of 'eating out' that are not however, predominantly financially segregated. One of the ways that participants value social eating initiatives is because they are affordable: "I come here for value for money, as I am in receipt of ESA and cannot afford to have a decent meal". The low-pay rather than no-pay nature of social eating facilitates practices of access and entry to eating spaces, reciprocity and commensality without the stigma associated with charity.

The non-financially oriented service provision of social eating constructs practices of contribution wherein customers can not only achieve performances of generosity but are framed as agents who have useful 'skills', 'experience' and 'talents' that find expression through the multiple entry points of voluntary activity that a community food initiative requires. The practices of helping out around the mealtime - whether using surplus rather than allowing it to enter landfill, collecting and sorting the food, serving, washing up or clearing down the space - might be understood as forms of alimentary contribution. We use this term to describe the 'hunger for social inclusion' (Pfeiffer et al. 2015:485) but it importantly also encompasses the broader practices of contribution that are non-transactional but deeply valuable to participants, and which also include the desires to engage in sustainable forms of food consumption compared to the intensification of consumption often associated with poverty consumers (Pfeiffer et al. 2015). Sustained through the domestic sphere and translated into a public, charitable setting, helping out here, is framed as performatively upholding the ethos and the symbolic value of broader social contribution. 


\section{Helping Out- examples of codes understood as elements and linkages of practices}

Material Elements-Service and Organisation, Community space, Church and Community,

Community, Networks and partners, Shared tables, Serving meals, Paid-for mead, Dinner time, Hall,

Social eating model

Meanings Elements- Service to the community, Giving back, Worthwhile cause, Getting involved, With not for, Interaction, Cooperation, Inclusive, Non-judgemental, Welcoming, Good company, Feeling valued, Making a difference, Contributary, Having a role

Competencies Elements-Leadership, Networking, Sharing, Signposting, Volunteers, Conversations, Queuing, Taking payments, Volunteer cooks, Setting up and clearing down

Linkages from the domestic sphere- Helping out, Dinner time, Good company, Washing up, Cooking for others, Celebrating

Linkages to food aid-Surplus food, Pay it forward, Free food, Food waste, Affording food, No or Low choice, Donation, Non-means tested, Free-items, Not for profit

Linkages from environmental tropes- Not wasting food, Food waste, Surplus, Sharing food, Using surpluses, Environment

\section{Compound Practice of Alimentary Participation}
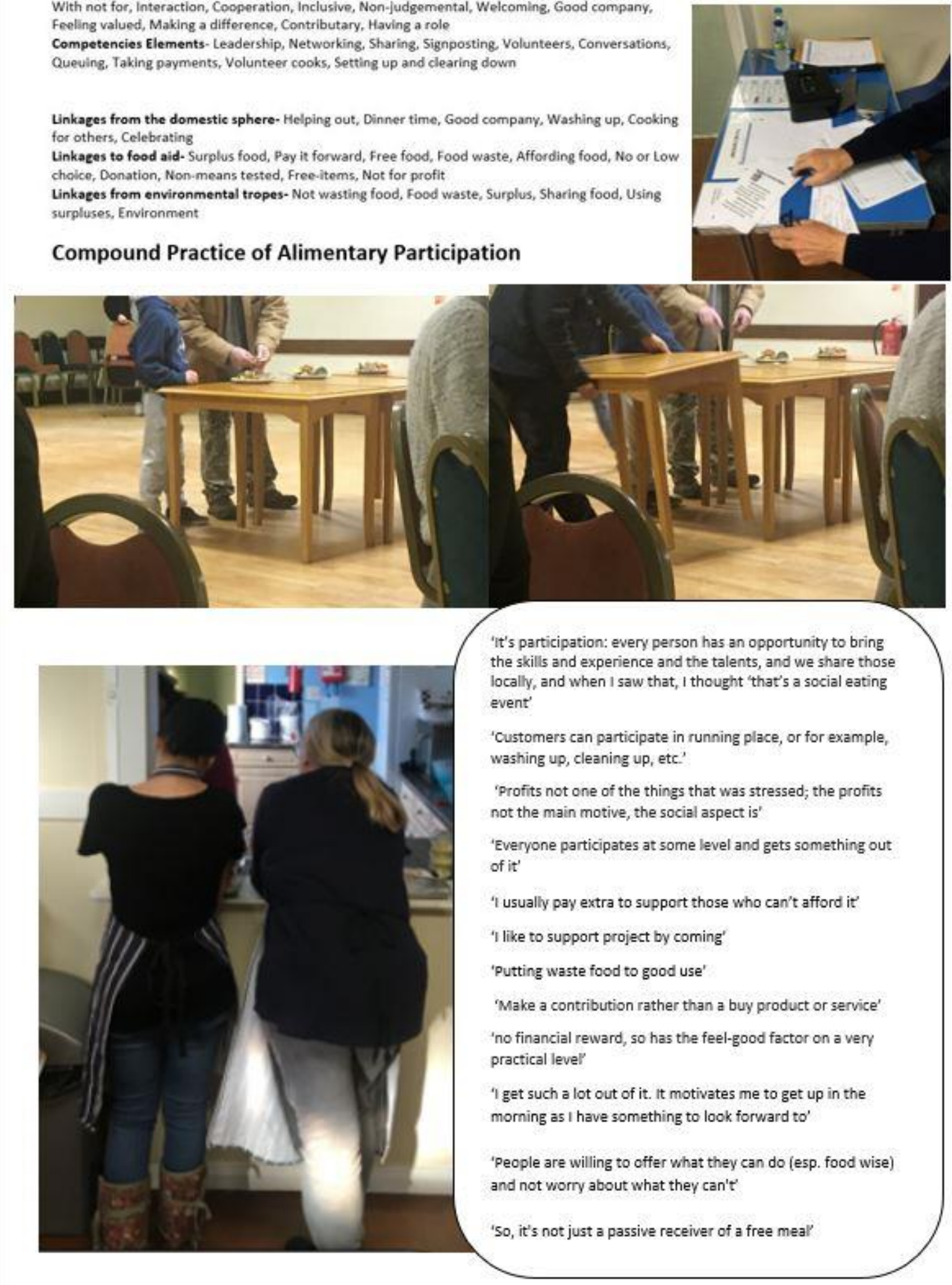

Figure 7. Alimentary contribution montage 
Alimentary contribution is an ongoing developmental process for many participants of social eating initiatives. Typically, people move from more passive consumers of meals in their early experiences of these initiatives to later actively shaping the planning and preparation of mealtimes, organising the physical and social arrangements of the spaces, and fostering an inclusive, helpful environment for other people to participate: "I moved to (here) in August knowing no residents- so it's a good meeting point. The idea of overpaying to help the less fortunate appeals".

A similar phenomenon has been recognised in the sociological literature on foodbanks where recipient-donor roles are switched as people become 'active citizens' volunteering to support others in need (Garthwaite 2017; Cloake et al. 2017), and in social eating initiatives this type of agency is a widespread hallmark of participation: "I... appreciate the initiative of encouraging people to contribute to eating alongside under-privileged people and paying for meals for them". Something as seemingly mundane as customers moving tables and chairs to eat with another table shows how domestic practices of agency around spatial organisation can be reconstituted within public social eating initiatives; creating environments that are constructed as intimate, customisable and participative. As social eating participants become more embedded through repeat attendance this temporal rhythming helps to engender a sense of belonging.

This social dynamic reframes the serving and eating of surplus foods not as something that is simply done to people as a consequence of top-down or structuralist food insecurity pressures, but is instead done by people as a consequence of their own agency, repurposing surpluses by creating new spaces for their own enjoyment while also helping other people: "Lucky we are here to eat this. Not only the meal, together, but otherwise it' $\mathrm{d}$ be tipped. What a waste!".

\subsection{Performances of care}

"A safe and welcoming place with food at its heart" is how one participant described a social eating initiative. Commensality enables a whole range of 'performances of care' (Murcott 1983a; Van Esterik 1995; Meah and Jackson 2017), for example being 'welcomed' by 'greeters', chatting in the queue for food, 'paying meals forward', entertaining other participants through musical performance, supporting the initiative through funding or by attending or 'volunteering', having a favoured cook or experiencing the meal as being 'made 
with love'. As one diner mused 'I would still choose here over an expensive place in town because of the socialising".

Socialising- examples of codes understood as elements and linkages of practices

Materials Elements- Eating together, Communicating, Relationship and status, Intergenerational, Families, Elders and aging, Old friends, Neighbours, Community hall, Space to play, Local, Nearby Meanings Elements- Health, Ethical, Spiritual action, Community spirit, Struggle, Exclusion, Being cared for, Presence, Connecting people, Company, Participatory, Intentional practice

Competencies Elements- Greeters, Volunteers, Weekly attendance, Attendance, Self-help

Linkages from the domestic and kinship sphere-Safe, warm and comfortable place, Familiar, Friendly

Linkages from other social activities- Enjoyment, Community spirit, Different people getting together, Meeting new people, Something to look forward to, Good company, Getting out of the house, Advertising, Logos, Opening times

\section{Compound Practice of Performances of Care}
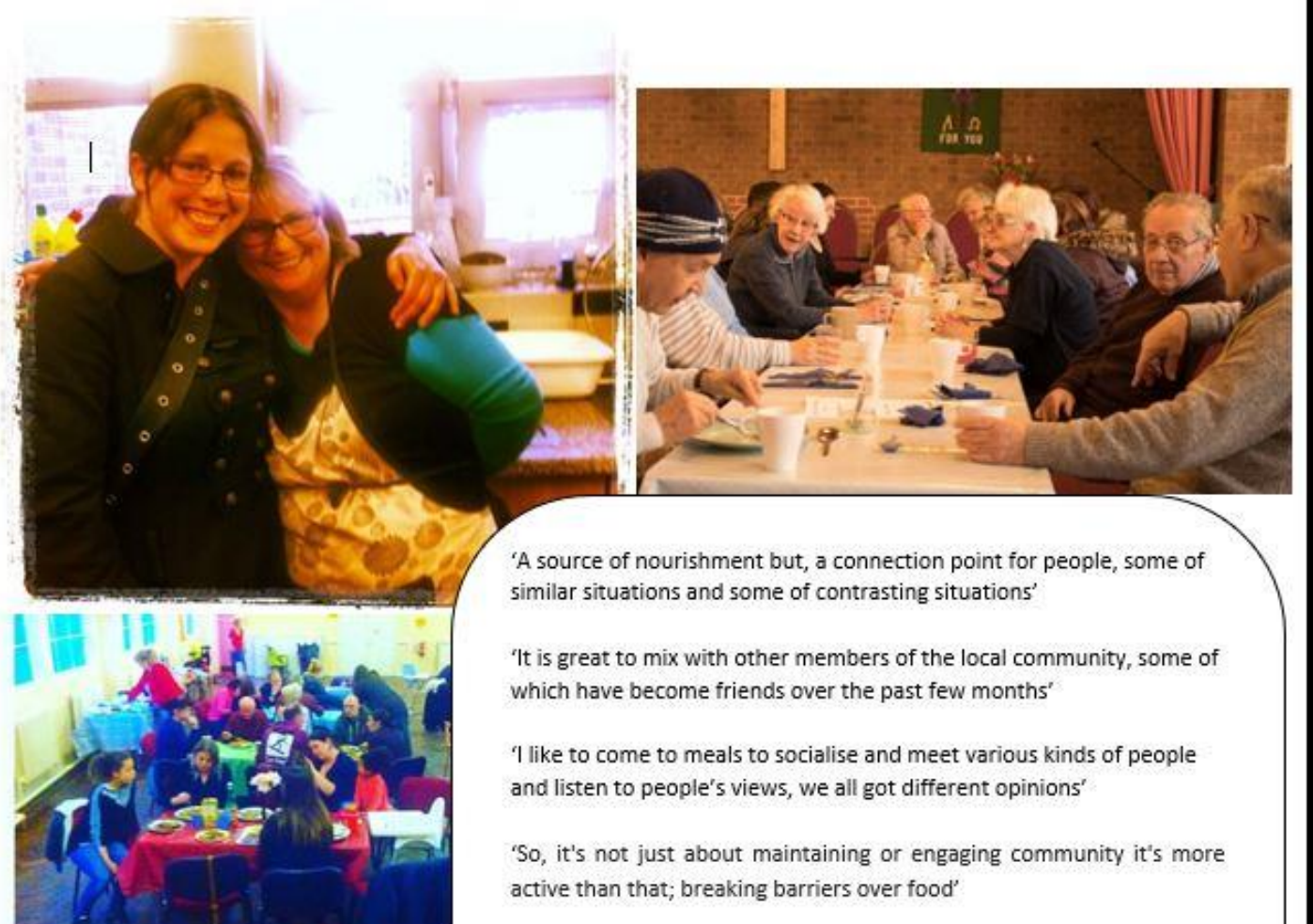

'It is great to mix with other members of the local community, some of which have become friends over the past few months'

I like to come to meals to socialise and meet various kinds of people and listen to people's views, we all got different opinions'

'So, it's not just about maintaining or engaging community it's more active than that; breaking barriers over food'

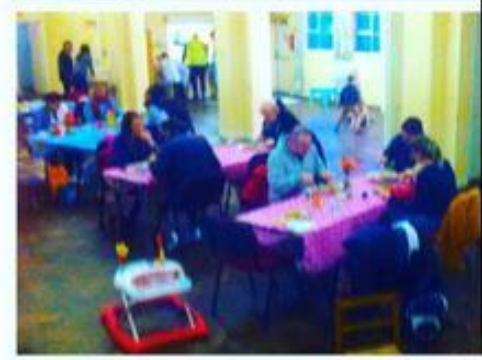

'A safe and welcoming space or place with food at the heart'

'Bringing different people together - so important at this political moment'

'Sense of belonging and connectedness'

'This group- the name says it all. Friendship and company'

It's nice for our little boy to come and meet other children from the village, have a play and a good meal, too. It's good for him to socialise outside his usual group of friends/family'

Figure 8. Performances of care montage. 
A range of elements compound as practices to express caring, friendship, companionship, participation, non-judgement and inclusion at social eating initiatives.

The spaces managed by social eating initiatives also serve as a springboard for secondary caregiving and social provision. Through fieldwork we observed the presence of employment specialists, welfare and benefits advisors, loneliness charities, and a wide range of social activists attending social eating initiatives. The communal focus around a meal creates a unique opportunity to engage people as collectives. Taken together the varied performances of care break the framing of social eating initiatives as charity or a food service proxy for poverty consumers, and instead reveals them as transformative sites of mutual aid, with just as much focus on developing new social structures as on responding to existing systemic pressures (Cloake et al. 2017). An interviewee suggested "So, it's not just about maintaining or engaging community, it's more active than that; breaking barriers over food!".

In the montage, the images convey a sense of 'togetherness' with volunteers embracing, diners sitting in proximity to each other, smiling and looking 'at ease'. As one customer reflected: "I get a three-course, homemade meal made for me" and another spoke of food being 'made with love'. Herein, performances of care; caregiving, socialising and togetherness manifested around the commonality of commensality.

Fundamentally, the lens of commensality reframes social eating initiatives, showing how intersecting practices decentre financial eligibility, charitable-deservedness, or the capacity to engage in the commercial food service market, and instead valorise social 'connection', 'contribution' and 'participation'. These spaces are nexuses wherein "some of similar situations and some of contrasting situations" can engage in meal centred mutuality. The practices which combine to construct experiences of feeling 'welcomed', of 'having a role', of 'being cared for' and engaging as a 'community' of eaters express the 'potent and persistent' need for humans to engage in commensality (Higgs 2015; Dunbar 2017).

\section{Conclusion - Revealing the value of social eating initiatives}

This study has addressed community food initiatives that use surplus food through a practice theory informed approach to commensality to better understand the value of social eating initiatives to their participants. Social eating initiatives are not just a form of food aid provisioning, but are a co-ordination of social mechanisms where broader, restructuring values 
of commensality manifest. Compound practices of social eating initiatives can be conceptualised not as a replacement or erosion of community commensality with charitable commensality, but as a complex and enduring form of social life that is enjoyed and multiply valued by its participants. The predominance of participation and contribution, and particularly the focus on experiences of sociality and wellbeing, offers an elaborated and nuanced view of community groups as doing 'more than food' with surplus (Blake 2019a, c). The Nottinghamfocus, which prompts questions about the broader applicability of the findings within this paper, is confirmed by what Marovelli terms the 'connective tissue' of community commensality in other cities such as London (2019:190).

Each of the three practices of commensality described in this paper draw attention to the prosocial benefits that accrue through this form of organisation, though it should also be recognised that social eating initiatives are sustained with support from volunteers. Indeed, community commensality is particularly exposed to precarious support from the public and private sectors. Further uncertainty emerges as the initiatives are often unable to gain longterm guaranteed access to 'spaces' for social eating. As Marovelli reflects, these initiatives all see 'their local communities in flux, experiencing precariousness and uncertainties in their everyday urban lives' (2019:11). Social eating projects, whilst sustained in part by customer renumeration, remain subject to the precarity associated with the broader charitable food sector within austerity (Dowler and Caraher 2003). Nonetheless, the alimentary contribution articulated within social eating practices reflects a more expansive conception of participation as encompassing people's need to be both socially included, and be socially including, and may point to the need to design policies that 'speak to' people's deeper needs for social connection beyond those that can be bought in the marketplace of goods and services. Through engaging with participants to construct a portrait of the broader practices through which social eating is constituted, we reveal the values of sociality and contribution to social life. It is this connection to the deeper, 'potent and pervasive' practices of commensality (Higgs 2015: 42) that point to the development of food policies that are more durable and impactful, and which draw upon an ample repository of evidence from anthropology to public health that show that commensality is implicated in the ongoing organisation and structuration of social life (Dunbar 2017).

Social eating practices challenge the idea that surplus food is merely a waste stream, instead identifying how 'influential, symbolic, powerful and transformative food can be' (Coveney 2013:2). The revealed practices of alimentary participation and performances of care 
challenge the conception that social eating initiatives that use surplus foods are merely replacing community commensality with charitable commensality. Social eating initiatives are actively re-imagining how we respond to the perceived destructuring tendencies of food insecurity, alimentary exclusion, food wastage and the restructuring of familial and shared mealtimes. Adopting the lens of commensality through a practice theory-informed approach extends our understandings of community food groups who utilise surplus by revealing the range of practices that fabricate a social eating mealtime; elaborating a range of entry points for developing policies on these challenges in partnership with participants.

Social eating initiatives have implications far beyond the mealtime. These initiatives are part of a broader 'feed people first' (Baron et al. 2018) movement in which the intersections of corporate food donation, charitable redistribution and community food projects meet to guide the effective redirection of edible food surpluses to those citizens suffering from food insecurity, but also to those seeking friendship, company and experiences of caring, through the medium of commensality. As Dunbar reflects, "those who eat socially more often feel happier and are more satisfied with life, are more trusting of others, are more engaged with their local communities, and have more friends they can depend on for support' (2017: 1). In this way, social eating initiatives may be conceived of as emerging not because of austerity, but in spite of the broader milieu; valued because they create opportunities to engage in the deep-set social need for commensal participation which is indeed threatened by the neo-liberal tropes of individuation and marketisation, and particularly by the social restructurings of austerity. These opportunities for social contribution sees social eating initiatives framed not as more palatably rebranded food aid, but as 'palaces for the people' (Klinenberg 2018); as examples of local nexuses necessary for normative values to be reinforced, and for new and necessary forms of social infrastructure to be materialised. 


\section{References}

BBC news, Nottingham (2018). 'Nottingham UK's first social eating city'. Available at: https://www.bbc.co.uk/news/av/uk-england-nottinghamshire-38669824/nottingham-s-ukfirst-social-eating-aim [Accessed 04.02.18].

Baron, S., Patterson, A., Maull, R. and Warnaby, G., (2018). Feed people first: A service ecosystem perspective on innovative food waste reduction. Journal of Service Research, 21(1), pp.135-150.

Beebeejaun, Y., Durose, C., Rees, J., Richardson, J. and Richardson, L. (2014) '”Beyond Text": Exploring Ethos and Method in Co-producing Research with Communities', Community Development Journal, 49, pp.37-53.

Blake, M., (2019a). More than just Food: Everyday food insecurity and resilient place making through community self- organising. Sustainability. 11(10), pp.2942.

Blake, M., (2019b). The Multiple Ontologies of Surplus Food. Europe Now. 27:1-8. Available at: https://www.europenowjournal.org/2019/05/06/the-multiple-ontologies-ofsurplus-food/ [Accessed 17.01.2020].

Blake, Megan. (2019c). 'Food Ladders: A multi-scaled approach to everyday food security and community resilience'. Available at Researchgate: https://www.researchgate.net/publication/333878382_Food_Ladders_A_multiscaled_approach_to_everyday_food_security_and_community_resilience [Accessed 7.5.2020].

Brannen, J., O'Connell, R., Mooney, A. (2013) 'Families, meals and synchronicity: eating together in British dual earner families'. Community, Work \& Family, 16(4), pp.417434.

Björgvinsson, E., Ehn, P. and Hillgren, P.A., (2010), November. Participatory design and" democratizing innovation". In Proceedings of the 11th Biennial participatory design conference, pp. 41-50. 
Block, L. G., Grier, S. A., Childers, T. L., Davis, B., Ebert, J. E.J., Kumanyika, S., Laczniak, R. N., Machin, J. E., Motley, C. M., Peracchio, L., Pettigrew, S., Scott, M., Van Ginkel B., Mirjam N.G. (2011). From Nutrients to Nurturance: A Conceptual Introduction to Food Well-Being, Journal of Public Policy \& Marketing (2011) 30(1), pp.5-13.

Bublitz, M., Peracchio, L., Andreasen, A., Kees, J., Kidwell, B., Miller, E., Motley, C., Peter, P., Rajagopal, P., Scott, M., Vallen, B. (2013). Promoting positive change: Advancing the food well-being paradigm. Journal of Business Research, 66(8), pp.1211.

Caplan, P. (2017) Food poverty and food aid in 21st century UK: a view from anthropology. Available at: https://blogs.lse.ac.uk/politicsandpolicy/an-anthropologicalperspective-on-food-poverty-in-uk/ [Accessed 22.01.2019].

Caraher, M. and Dowler, E. (2014) 'Food for poorer people: conventional and "alternative" transgressions', in Goodman, M. and Sage, C. (eds.), Food Transgressions: Making Sense of Contemporary Food Politics, Farnham: Ashgate, pp.227-46.

Caraher, M. and Furey, S. (2017) Is it appropriate to use surplus food to feed people in hunger? Short-term Band-Aid to more deep rooted problems of poverty. Food Research Collaboration. Available at: http://foodresearch.org.uk/wp-content/uploads/2017/01/FinalUsing-food-surplus-hunger-FRC-briefing-paper-24-01-17-.pdf. [Accessed 4.10. 2019].

Caraher, M. and Furey, S., (2018). The Economics of Emergency Food Aid Provision. Springer Books.

Carlile, P. R., Nicolini, D., Langley, A., and Tsoukas, H. (eds.) (2013) 'How matter matters: Objects, artifacts, and materiality in organization studies'. Oxford: Oxford University Press.

Carpiano, R.M., (2009). Come take a walk with me: The "Go-Along" interview as a novel method for studying the implications of place for health and well-being. Health \& place, 15(1), pp.263-272.

Carson, E (2014) 'Canadian food banks and the depolitization of food insecurity at the individual and community levels'. Canadian Review of Social Policy. 70, pp. 7-21. 
Charles, N. and Kerr, M. (1988) Women, food and families. Manchester: Manchester University Press.

Chou, C., Kerner, S. and Warmind, M. (eds.) (2015) Commensality: From Everyday Food to Feast, Bloomsbury Academic.

Chun-Chung, Chow \& Crowe, Kelsey. (2005). 'Community-Based Research and Methods in Community Practice.' In Weil (ed.), The Handbook of Community Practice, pp.604-619. Thousand Oaks: Sage Publications, Inc.

Cloke, P., May, J., \& Williams, A. (2017). The geographies of food banks in the meantime. Progress in Human Geography, 41(6), pp.703-726.

Coventry University (2020) 'Research Ethics'. Available at: https://www.coventry.ac.uk/research/about-us/research-ethics/ [Accessed 1.9.20)

Davies, A.R., Edwards, F., Marovelli, B., Morrow, O., Rut, M. and Weymes, M., (2017). Making visible: Interrogating the performance of food sharing across 100 urban areas. Geoforum, 86, pp.136-149.

DeVault, M. (1991) Feeding the family: The social organization of caring as gendered work. Chicago, IL: University of Chicago Press.

DiSalvo, C. (2012) Adversarial design. Cambridge, Massachusetts: The MIT Press.

DiSalvo, C., Louw, M., Holstius, D., Nourbakhsh, I. and Akin, A. (2012) 'Toward a public rhetoric through participatory design: Critical engagements and creative expression in the neighbourhood networks project'. Design Issues, 28(3), pp.48-61.

Douglas, F., Sapko, J., Kiezebrink, K. and Kyle, J., (2015). Resourcefulness, desperation, shame, gratitude and powerlessness: Common themes emerging from a study of food bank use in Northeast Scotland. AIMS Public Health, 2(3), pp.297.

Dowler, E.A. and O’Connor, D., (2012). Rights-based approaches to addressing food poverty and food insecurity in Ireland and UK. Social science \& medicine, 74(1). pp.44-51

Doyle, R. and Davies, A.R., (2013). Towards sustainable household consumption: exploring a practice oriented, participatory backcasting approach for sustainable home heating practices in Ireland. Journal of Cleaner Production, 48, pp.260-271. 
Dunbar, R. I.M. (2017) 'Breaking bread: the functions of social eating', Adaptive Human Behaviour and Physiology, 3 (3), pp. 198-211.

Ehn, P., (2008). Participation in design things. In Proceedings Participatory Design Conference 2008. ACM.

Elliott, V. (2018). 'Thinking about the Coding Process in Qualitative Data Analysis'. The Qualitative Report, 23 (11), How To Article 5, pp.2850-2861.

Evans, D. (2012) 'Beyond the Throwaway Society: Ordinary Domestic Practice and a Sociological Approach to Household Food Waste', Journal of Sociology, (46) 1.

Farías, I. and Bender, T., (2010). Reassembling the city: networks and urban imaginaries. Urban assemblages: how actor-network theory changes urban studies, pp.303323.

Färber, A., (2014). Low-budget Berlin: Towards an understanding of low-budget urbanity as assemblage. Cambridge Journal of Regions, Economy and Society, 7(1), pp.119136.

Faridi, Z., Grunbaum, A. J., Gray, B. S., Franks, A., Simoes, E. (2007). 'Communitybased participatory research: necessary next steps'. Prevention of Chronic Diseases, 4:A70.

Fischler, C. (2011) 'Commensality, society and culture', Social Science Information, 50(3-4), pp.528-548, SAGE Publications.

Foodhall webpage. Available at: https://www.foodhallproject.org/. [Accessed 20.04.20].

Garthwaite, K.A., Collins, P.J. and Bambra, C., (2015). Food for thought: An ethnographic study of negotiating ill health and food insecurity in a UK foodbank. Social science \& medicine, 132, pp.38-44.

Garthwaite, K., (2016). Stigma, shame and'people like us': an ethnographic study of foodbank use in the UK. Journal of Poverty and Social Justice, 24(3), pp.277-289.

Garthwaite, K., 2017. 'I feel I'm giving something back to society': constructing the 'active citizen' and responsibilising foodbank use. Social Policy and Society, 16(2), pp.283292. 
Garcia, C. M., Eisenberg, M. E., Frerich, E. A., Lechner, K. E., Lust, K. (2012) 'Conducting Go-Along Interviews to Understand Context and Promote Health'. Qualitative Health Research, 22(10), pp.1395-1403.

Garrone, P., Melacini, M. and Perego, A., (2014). Opening the black box of food waste reduction. Food policy, 46, pp.129-139.

Giacoman, C., (2016). The dimensions and role of commensality: A theoretical model drawn from the significance of communal eating among adults in Santiago, Chile. Appetite, 107, pp.460-470.

Giménez, E., H. and Shattuck, A. (2011) Food crises, food regimes and food movements: rumblings of reform or tides of transformation?, The Journal of Peasant Studies, 38(1), pp.109-144.

Glaser, B. (1978). Theoretical sensitivity: Advances in the methodology of grounded theory. Mill Valley, CA: Sociology Press.

Goffman, E., (2002). The presentation of self in everyday life. [1959]. Garden City, NY, 259.

Goodman, D. and Goodman, M.K., (2007). Localism, livelihoods and the 'postorganic': changing perspectives on alternative food networks in the United States. In: Maye, D., Holloway, L. and Kneafsey, M. (eds.) Alternative Food Geographies: Representation and Practice. Elsevier, Oxford, pp.23-38

Grieshaber, S. (1997) 'Mealtime rituals: Power and resistance in the construction of mealtime rules'. The British Journal of Sociology, 48(4), pp. 649-666.

Halkier, B. and Jensen, I. (2011) 'Methodological Challenges in using practice theory in consumption research. Examples from a study handling nutritional contestations of food consumption', Journal of Consumer Culture, 11(1), pp. 101-123.

Halkier, B., Katz-Gerro, T. and Martens, L., (2011) Applying practice theory to the study of consumption: Theoretical and methodological considerations. Journal of Consumer Culture, 11 (1), pp.3-13.

Healy, A.E., (2019) Measuring food poverty in Ireland: The importance of including exclusion. Irish Journal of Sociology, 27(2), pp.105-127. 
Higgs, S., (2015). Social norms and their influence on eating behaviours. Appetite, 86, pp.38-44.

Holmes, H. and Hall, S.M. eds., (2020). Mundane Methods: Innovative ways to research the everyday. Manchester University Press.

Iacovidou, E., Velis, C.A., Purnell, P., Zwirner, O., Brown, A., Hahladakis, J., Millward-Hopkins, J. and Williams, P.T., (2017). Metrics for optimising the multi-dimensional value of resources recovered from waste in a circular economy: A critical review. Journal of Cleaner Production, 166, pp.910-938.

Jones, P., Bunce, G., Evans, J., Gibbs, H. and Hein, J.R., (2008). Exploring space and place with walking interviews. Journal of research practice, 4(2), D2-D2.

Kindon, S., Pain, R., and Kesby, M. (eds), (2007). Participatory Action Research Approaches and Methods: Connecting People, Participation, and Place. Routledge: Abingdon, UK

Klinenberg, E. (2018) Palaces for the People: How Social Infrastructure can Help Fight Inequality, Polarization, and the Decline of Civic Life. Crown Publishing Group.

Knorr-Cetina, K., von Savigny, E. and Schatzki, T.R. (eds.), (2001). The practice turn in contemporary theory. Routledge.

Kusenbach, M. (2003), "Street phenomenology: the go-along as ethnographic research tool" Ethnography, 4(3), pp. 455-485.

Lalor, D. (2014) 'Feeding the Gaps: food poverty and food surplus redistribution in Oxford. 2014': Oxford in Caraher, M., Furey, S., Is it appropriate to use surplus food to feed people in hunger? Short-term Band-Aid to more deep rooted problems of poverty, 26 January 2017. Food Research Collaboration Policy Brief.

Lambie-Mumford, H. and Dowler, E. (2015) 'Review Article. Hunger, Food Charity and Social Policy- Challenges Faced by the Emerging Evidence Base'. Social Policy \& Society 14(3), pp.497-506.

Lansley, S. and Mack, J., (2015). Breadline Britain: The rise of mass poverty. Oneworld Publications. 
Lawton, C. (2017). 'Ordinary Working Families in Nottingham and the UK. Technical Working Paper: Objective and Subjective Measures of Income and Earnings'. Nottingham Civic Exchange. Available at: http://irep.ntu.ac.uk/id/eprint/31650/1/9093_Lawton.pdf, [Accessed 1.9.20].

LeDantec, C.A.L. and DiSalvo, C., (2013). Infrastructuring and the formation of publics in participatory design. Social Studies of Science, 43(2), pp.241-264.

Linderson, A., (2010). To enter the kitchen door to people's lives: A Multi-Method Approach in the Research of Transnational Practices among Lifestyle Migrants. Recreation and Society in Africa, Asia and Latin America, 1(1).

Loopstra, R. and Tarasuk, V., (2012). The relationship between food banks and household food insecurity among low-income Toronto families. Canadian Public Policy, 38(4), pp.497-514.

Lorenz, S., (2015). Having no choice: Social exclusion in the affluent society. Journal of Exclusion Studies, 5(1), pp.1-17.

Luca, N., Smith, M., Hibbert, S., Doherty, B. (2019) House of Lords Select Committee Submission for 'Food, Poverty and the Environment- 'How to make a healthy, sustainable diet accessible and affordable for everyone?', Written evidence (FPO0032). Available at: http://data.parliament.uk/writtenevidence/committeeevidence.svc/evidencedocument/foodpoverty-health-and-environment-committee/food-poverty-health-and-theenvironment/written/105296.html on 24.4.20. [Accessed on 24.4.20]

Lund, T.B. and Gronow, J., (2014). Destructuration or continuity? The daily rhythm of eating in Denmark, Finland, Norway and Sweden in 1997 and 2012. Appetite, 82, pp.143-153.

Maguire, E.R., Burgoine, T. and Monsivais, P., (2015). Area deprivation and the food environment over time: A repeated cross-sectional study on takeaway outlet density and supermarket presence in Norfolk, UK, 1990-2008. Health \& Place, 33, pp.142-147.

Mannay, D., (2010). Making the familiar strange: Can visual research methods render the familiar setting more perceptible? Qualitative research, 10(1), pp.91-111.

Mäkelä, J., (2009). Meals: the social perspective. In Meals in science and practice, pp. 37-49. Woodhead Publishing. 
Marovelli, B., (2019). Cooking and eating together in London: food sharing initiatives as collective spaces of encounter. Geoforum, 99, pp.190-201.

Martens, L. (2012) Practice 'in talk' and talk 'as practice': Dish washing and the reach of language. Sociological Research Online 17(3), p.22. Available at: http://www.socresonline.org.uk/17/3/22.html [Accessed 21.04.20].

Masson, E., Bubendorff, S. and Fraïssé, C., (2018). Toward new forms of meal sharing? Collective habits and personal diets. Appetite, 123, pp.108-113.

Mathie, A. and Cunningham, G., (2003). From clients to citizens: Asset-based community development as a strategy for community-driven development. Development in practice, 13(5), pp.474-486.

Meah, A., and Jackson, P. (2017). 'Convenience as care: Culinary antinomies in practice'. Environment and Planning A: Economy and Space, 49(9), pp. 2065-2081.

Mestdag, I., (2005). Disappearance of the traditional meal: temporal, social and spatial destructuration. Appetite, 45(1), pp.62-74.

Middleton, G., Mehta, K., McNaughton, D., Booth, S., (2018). 'The experiences and perceptions of food banks amongst users in high-income countries: An international scoping review'. Appetite. 120, pp.698-708.

Midgley, J. L. (2014) 'The logics of surplus food redistribution'. Journal of Environmental Planning and Management (0)1, pp.1-21. Routledge.

Moragues-Faus, A., Marsden, T. (2017) 'The political ecology of food: Carving 'spaces of possibility' in a new research agenda'. Journal of Rural Studies, 55, pp.275-288.

Murcott, A. (1982) 'On the social significance of the cooked dinner, in South Wales'. Social Science Information, 21(4/5), pp.677-695.

Murcott, A. (1983a) 'Cooking and the cooked: A note on the domestic preparation of meals' in Murcott, A. (ed.), The sociology of food and eating, pp.178-193. Aldershot: Gower.

National Food Service (2020) National Food Service Vision Available at: https://www.nationalfoodservice.uk/vision. [Accessed on 24.4.20]

Nicolini, D., (2012). Practice theory, work, and organization: An introduction. OUP Oxford. 
Pfeiffer, S., Ritter, T., Oestreicher, E. (2015) 'Food Insecurity in German households: Qualitative and Quantitative Data on Coping, Poverty Consumerism and Alimentary Participation'. Social Policy and Society, 14(3), pp.483-495

Power, N., G., Norman, M., E. and K Dupré, K. (2014) Rural youth and emotional geographies: how photovoice and words-alone methods tell different stories of place, Journal of Youth Studies, 17(8), pp.1114-1129.

Poppendieck, J. (2014) 'Food assistance, hunger and the end of welfare in the USA' in Riches, G. and Silvasti, T. (eds) First World Hunger Revisited: Food charity or the Right to Food? Basingstoke: Palgave Macmillan.

Purdam, K., Garratt, E.A. and Esmail, A., (2016). Hungry? Food insecurity, social stigma and embarrassment in the UK. Sociology, 50(6), pp.1072-1088.

Radimer, K.L., Olson, C.M. and Campbell, C.C., (1990). Development of indicators to assess hunger. The Journal of nutrition, 120(suppl_11), pp.1544-1548.

Reid, C. and Alonso, M., (2018). Imagining inclusion: Uncovering the upstream determinants of mental health through Photovoice. Therapeutic Recreation Journal, 52(1), pp.19-41.

Riches, G. and Silvastri, T. (eds) (2014). 'First World Hunger Revisited: Food Charity or the Right to Food?'. Basingstoke: Palgrave Macmillan.

Riches, G. and Gerlings, K. (2019). 'Is 'Left Over' Food for 'Left Behind' People the Best We Can Do? Domestic hunger should not be left to charity and corporate food waste. The Tyee online edition, $16^{\text {th }}$ May 2019. Available at: at: https://thetyee.ca/Opinion/2019/05/16/Left-Over-Food-Left-Behind/ [Accessed on 26.4.20]

Reason, P. and Bradbury, H. (2006). 'Introduction.' In Reason, P., Bradbury, H., (eds.). The Handbook of Action Research: Participative Inquiry and Practice, (Concise Edition). Thousand Oaks, CA.: Sage.

Saxena, L.P., (2018). How social supermarkets are filling a gap in austerity Britain'. Available at: https://pureportal.coventry.ac.uk/en/publications/how-social-supermarkets-arefilling-a-gap-in-austerity-britain [Accessed 21.3.2020]. 
Shattuck, A., Schiavoni, C., M., and VanGelder, Z. (2015) 'Translating the Politics of Food Sovereignty: Digging into Contradictions, Uncovering New Dimensions', Globalizations, 12(4), pp.421-433.

Shove, E., \& Pantzar, M. (2005). Consumers, Producers and Practices: Understanding the invention and reinvention of Nordic walking. Journal of Consumer Culture, 5(1), pp.4364.

Shove, E., Pantzar, M., and Watson, M. (2012) The dynamics of social practice: everyday life and how it changes. Los Angeles: SAGE.

Sobal, J., (2000). Sociability and meals: Facilitation, commensality, and interaction. Dimensions of the meal: The science, culture, business, and art of eating, pp.119133.

Social Eating Network (2020), Contact page. Available at : https://www.socialeatingnetwork.org [Accessed 12.8.20].

Strauss, A. and Corbin, J., (1994). Grounded theory methodology. Handbook of qualitative research, 17, pp.273-85.

Strauss, A., and Corbin, J. (1998). Basics of qualitative research: Techniques and procedures for developing grounded theory (2nd ed.). Thousand Oaks, CA: Sage.

Tarasuk, V.S. and Beaton, G.H., (1999). Household food insecurity and hunger among families using food banks. Canadian Journal of Public Health, 90(2), pp.109-113.

Tarasuk, V., and J.M. Eakin. (2005). 'Food Assistance through "Surplus" Food: Insights from an Ethnographic Study of Food Bank Work'. Agriculture and Human Values 22 (2), pp.177-186.

Twine, R. (2015) 'Understanding snacking through a practice theory lens'. Sociology of Health \& Illness, 37 (8), pp.1270-1284.

Valentine, G. (1999) 'Eating in: home, consumption and identity’. Sociological Review, 47(3), pp.491-524. 
Van der Horst, H., Pascucci, S., and Bol, W. (2014). 'The "dark side" of food banks? Exploring emotional responses of food bank receivers in The Netherlands'. British Food Journal, 116(9), pp.1506-1520.

Van Esterik, P. (1995). 'Care, Caregiving, and Caregivers'. Food and Nutrition Bulletin, 16(4), pp. 1-11.

Keller, M., Kiisel, M. and Vihalemm, T., (2015). From intervention to social change: A guide to reshaping everyday practices. Ashgate Publishing, Ltd.

Warde, A., (1999). Convenience food: space and timing. British Food Journal, 101(7), pp.518-527.

Warde, A (2005) 'Consumption and theories of practice'. Journal of Consumer Culture (5), pp.131-53.

Warde, A. (2014). 'After taste: Culture, consumption and theories of practice'. Journal of Consumer Culture, 14(3), pp.279-303.

Warde, A., (2016). The practice of eating. John Wiley \& Sons.

Warde, A. and Hetherington, K, (1994). English households and routine food practices: a research note. The Sociological Review, 42(4), pp.758-778.

Wiggins, S., Keats, S., Han, E., Shimokawa, S., Alberto, J., Hernandez, V. and Claro, R.M., (2015). The rising cost of a healthy diet: changing relative prices of foods in high-income and emerging economies. Overseas Development Institute Report May, 67.

Williams, A., Cloke, P., May, J. and Goodwin, M., (2016). 'Contested space: The contradictory political dynamics of food banking in the UK'. Environment and Planning A: Economy and Space, 48(11), pp.2291-2316.

Wills, W.J., Dickinson, A.M., Meah, A. and Short, F., (2016). Reflections on the use of visual methods in a qualitative study of domestic kitchen practices. Sociology, 50(3), pp.470-485.

Wills, J., (2016). (Re) Locating community in relationships: questions for public policy. The Sociological Review, 64(4), pp.639-656. 
WRAP (2020). 'Food surplus and waste in the UK - key facts'. Updated January 2020. Section 1.0-UK food and drink surplus and waste arisings. Available at: https://wrap.org.uk/sites/files/wrap/Food_\%20surplus_and_waste_in_the_UK_key_facts_Jan 2020.pdf [Accessed on 11.5.2020].

Yates, L., (2015). Rethinking prefiguration: Alternatives, micropolitics and goals in social movements. Social Movement Studies, 14(1), pp.1-21.

Yates, L. and Warde, A., (2017). Eating together and eating alone: meal arrangements in British households. The British journal of sociology, 68(1), pp.97-118. 